\title{
Wolbachia strain wAlbB blocks replication of flaviviruses and alphaviruses in mosquito cell culture
}

O'mezie Ekwudu ${ }^{1,2,3}$, Gregor J. Devine ${ }^{3}$, John G. Aaskov ${ }^{1}$ and Francesca D. Frentiu ${ }^{1 *}$ (D)

\begin{abstract}
Background: Wolbachia pipientis are bacterial endosymbionts of arthropods currently being implemented as biocontrol agents to reduce the global burden of arboviral diseases. Some strains of Wolbachia, when introduced into Aedes aegypti mosquitoes, reduce or block the replication of RNA viruses pathogenic to humans. The wAlbB strain of Wolbachia was originally isolated from Aedes albopictus, and when transinfected into Ae. aegypti, persists in mosquitoes under high temperature conditions longer than other strains. The utility of wAlbB to block a broad spectrum of RNA viruses has received limited attention. Here we test the ability of wAlbB to reduce or block the replication of a range of Flavivirus and Alphavirus species in cell culture.

Methods: The C6/36 mosquito cell line was stably infected with the wAlbB strain using the shell-vial technique. The replication of dengue, West Nile and three strains of Zika (genus Flavivirus), and Ross River, Barmah Forest and Sindbis (genus Alphavirus) viruses was compared in wAlbB-infected cells with Wolbachia-free controls. Infectious virus titres were determined using either immunofocus or plaque assays. A general linear model was used to test for significant differences in replication between flaviviruses and alphaviruses.
\end{abstract}

Results: Titres of all viruses were significantly reduced in cell cultures infected with wAlbB versus Wolbachia-free controls. The magnitude of reduction in virus yields varied among virus species and, within species, also among the strains utilized.

Conclusion: Our results suggest that wAlbB infection of arthropods could be used to reduce transmission of a wide range of pathogenic RNA viruses.

Keywords: Arbovirus, Mosquito, Dengue, Zika, Ross River Virus, West Nile, Sindbis

\section{Background}

Mosquito-borne viruses contribute significantly to the global burden of infectious diseases. Two genera of viruses responsible for significant numbers of human disease cases are Flavivirus and Alphavirus. Dengue viruses (DENV) are the most important human

\footnotetext{
${ }^{*}$ Correspondence: francesca.frentiu@qut.edu.au

${ }^{1}$ School of Biomedical Sciences and Institute of Health and Biomedical Innovation, Queensland University of Technology, Herston, QLD 4006, Australia

Full list of author information is available at the end of the article
}

pathogens among the flaviviruses (family Flaviviridae), causing an estimated 390 million infections annually among the more than 2.5 billion people at risk of infection $[1,2]$. Zika virus (ZIKV) causes a mild febrile illness in adults and may result in foetal loss during pregnancy and congenital neural malformations in babies [3, 4]. West Nile virus (WNV) can cause encephalitis and is now endemic in Europe and North America [5, 6]. The Australian strain of $\mathrm{WNV}$, Kunjin virus $\left(\mathrm{WNV}_{\mathrm{KUN}}\right)$, also can cause encephalitis [7]. Within the genus Alphavirus (family Togaviridae), Ross River virus (RRV) and Barmah

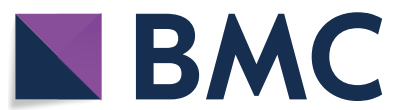

(c) The Author(s) 2020. This article is licensed under a Creative Commons Attribution 4.0 International License, which permits use, sharing, adaptation, distribution and reproduction in any medium or format, as long as you give appropriate credit to the original author(s) and the source, provide a link to the Creative Commons licence, and indicate if changes were made. The images or other third party material in this article are included in the article's Creative Commons licence, unless indicated otherwise in a credit line to the material. If material is not included in the article's Creative Commons licence and your intended use is not permitted by statutory regulation or exceeds the permitted use, you will need to obtain permission directly from the copyright holder. To view a copy of this licence, visit http://creativeco mmons.org/licenses/by/4.0/. The Creative Commons Public Domain Dedication waiver (http://creativecommons.org/publicdomain/ zero/1.0/) applies to the data made available in this article, unless otherwise stated in a credit line to the data. 
Forest virus (BFV) are two of the most common infections occurring in Australia and cause arthralgia and myalgia [8]. RRV also has caused outbreaks of disease in the Pacific, resulting in tens of thousands of cases [9]. Sindbis virus (SINV) infections are associated with a rash and mild fever in humans and have caused disease outbreaks in northern Europe [10,11].

Transinfection of mosquito vector populations with Wolbachia has been proposed as an arbovirus biocontrol measure that may be self-sustaining and environmentally friendly [12]. Wolbachia are obligate intracellular bacteria that have evolved diverse ways to manipulate reproduction in their arthropod hosts in order to invade host populations $[13,14]$. It is estimated that between $40-60 \%$ of all insect species are infected with diverse strains of Wolbachia $[15,16]$. When transinfected into Aedes aegypti mosquitoes, some Wolbachia strains block the replication and transmission of viruses such as dengue, Zika and chikungunya (CHIKV) [17-22]. The pathogen-blocking ability of Wolbachia has resulted in this biocontrol agent being trialled in the field in at least 12 countries (http://www.worldmosquitoprogram.org), with the aim of making native mosquito populations refractory to arbovirus transmission [22-24].

The ability of Wolbachia to block pathogen replication depends, in part, on the strain of bacteria being used $[25,26]$. Stable infections have been established in Ae. aegypti with several strains, including wMelPop [27] and $w$ Mel [18], both of which are native to Drosophila melanogaster. $w$ MelPop over-replicates in its hosts and is highly effective in restricting replication and transmission of a broad range of human arboviruses, including DENV $[17,20]$, CHIKV $[17,28]$, yellow fever virus $[17,28]$ and WNV [19]. However, wMelPop is unlikely to invade and persist in wild populations due to its reduction of host fitness [26, 29-31]. $w$ Mel blocks the replication of DENV [18, 22, 32], ZIKV [33, 34] and CHIKV [35], without significantly reducing mosquito fitness [18]. It is also able to invade and persist in mosquito populations [23, 24, 36]. However, $w \mathrm{Mel}$ can be lost from the mosquito host when exposed to heat stress [37, 38], potentially reducing the extent of virus blocking and slowing the spread of Wolbachia through a vector population.

The Wolbachia strain wAlbB, isolated from Ae. albopictus mosquitoes, has been found to be more stable than $w$ MelPop and $w$ Mel under high heat conditions both in the laboratory [38] and the field [39]. At high temperatures, $w$ AlbB transinfected into Ae. aegypti mosquitoes, exhibited a high and stable density of bacteria, and high maternal transmission fidelity [38-40]. wAlbB has invaded caged populations of Ae. aegypti [41], blocks DENV transmission in at least $40 \%$ of mosquitoes [20,40] and is currently being tested in the field in Malaysia [42].
Preliminary results from releases in Malaysia suggest that $w$ AlbB can persist in field mosquitoes, be maintained at high frequencies, and may significantly reduce dengue incidence [43]. Despite $w$ AlbB holding significant promise as a biocontrol agent, its ability to block the replication of a broad range of human arboviruses has not been systematically tested. Here, we test the ability of $w$ AlbB to block the replication of several flaviviruses and alphaviruses in mosquito cell lines.

\section{Methods \\ Mosquito cells and infection with wAlbB}

The Ae. albopictus cell line C6/36 [44] was maintained at $28{ }^{\circ} \mathrm{C}$ in RPMI-1640 medium containing $25 \mathrm{Mm}$ HEPES (Sigma-Aldrich, Castle Hill, Australia), supplemented with $10 \% \mathrm{v} / \mathrm{v}$ heat-inactivated foetal bovine serum (FBS, Gibco, Mt. Waverely, Australia) and 1\% v/v L-glutamine (Invitrogen, Carlsbad, USA). The wAlbB-infected cell line, designated $\mathrm{C} 6 / 36 . w \mathrm{AlbB}$, was generated by introducing $w \mathrm{AlbB}$ from Aa23 Ae. albopictus cells [45] into C6/36 cells using the shell vial technique, according to previously published methods [46, 47]. C6/36.wAlbB cells were maintained in 2:1 mixture of RPMI-1640 media buffered with HEPES (Sigma-Aldrich) and Schneider's Drosophila Modified medium (Lonza, Basel, Switzerland), supplemented with $10 \%$ v/v FBS and $1 \% \mathrm{v} / \mathrm{v}$ L-glutamine. Preliminary experiments (data not shown) indicated Schneider's Drosophila Modified medium (Lonza, Basel, Switzerland) was necessary for maintenance of $w \mathrm{AlbB}$ in cell culture. All insect cells were maintained at $28{ }^{\circ} \mathrm{C}$ and subcultured in maintenance media at a 1:3 ratio once each week for $\mathrm{C} 6 / 36$.wAlbB cells and 1:5 ratio twice a week for $\mathrm{C} 6 / 36$ controls.

Fluorescent in situ hybridization (FISH) for wAlbB detection C6/36.wAlbB cells and C6/36 control cells without Wolbachia were seeded into duplicate wells in chambered slides (Bio-Basic, Ontario, Canada) and incubated for $24 \mathrm{~h}$ at $28{ }^{\circ} \mathrm{C}$. Cell monolayers were washed with sterile phosphate buffered saline (PBS), fixed with ice-cold 4\% paraformaldehyde (PFA) (VWR Alfa, BioStrategy, Tingalpa, Australia) at $4{ }^{\circ} \mathrm{C}$ for $30 \mathrm{~min}$ and then washed three times in $0.1 \mathrm{M}$ phosphate buffer. The cells were dehydrated by sequential immersion of the slides, at $2 \mathrm{~min}$ intervals, in $70 \%, 95 \%$ and $100 \% \mathrm{v} / \mathrm{v}$ ethanol/water at room temperature. Hybridization was conducted overnight at $37{ }^{\circ} \mathrm{C}$ in a humidified container with hybridization cocktail II $+50 \%$ formamide (BioBasic, Ontario, Canada) containing $100 \mathrm{ng} / \mu \mathrm{l}$ of Cy5 labelled, Wolbachia-specific $16 S$ rRNA W2 oligonucleotide probe (5'-CY5-CTT CTG TGA GTA CCG TCA TTA TC-3) [48], synthesized at IDT DNA (Singapore). After hybridization, the slides were rinsed 
in $1 \times$ SSC buffer containing 10mM dithiothreitol (DTT) (AppliChem GmbH Germany), and then twice in $0.5 \times$ SSC buffer containing $10 \mathrm{mM}$ DTT. All washes were performed at $55{ }^{\circ} \mathrm{C}$ for $15 \mathrm{~min}$ each. Cells were then stained with $0.5 \mu \mathrm{g} / \mathrm{ml}$ DAPI (Sigma-Aldrich, Castle Hill, Australia) and images captured on a Zeiss epifluorescent microscope at $100 \times$ magnification. Signals from five separate microscope fields from 3 independent cell culture samples were analysed.

\section{Virus species and strains}

$\mathrm{WNV}_{\text {KUN }}$ (MRM 16 strain), RRV (T48), BFV (16313) and SINV (MRM39) were obtained from the World Health Organisation Collaborating Centre for Arbovirus Reference and Research at Queensland University of Technology, Australia. We used DENV serotype 2 strain ET300 (GenBank: EF440433) as a representative strain of dengue. The following strains of Zika virus were used: a Brazilian isolate (GenBank: KU365780), the French Polynesian isolate H/PF/2013 (GenBank: KJ776791) and the African genotype reference strain MR766. All virus stocks were propagated in C6/36 cells maintained as described above but with FBS supplementation reduced to $2 \%$. Culture supernatant was harvested 2 days following infection of cells with SINV, 3 days after RRV and BFV infections, and 4 days after $\mathrm{WNV}_{\mathrm{KUN}}$ infections. Supernatants were harvested 4 days post-infection (dpi) for ZIKV strain KU365780 and 5 dpi for ZIKV strains MR766 and H/PF/2013, and DENV-2 ET300. Cell debris was removed from culture supernatants by centrifugation at $4000 \times g$ for $10 \mathrm{~min}$ at $4{ }^{\circ} \mathrm{C}$ and virus concentrated by ultrafiltration through a $100 \mathrm{kDa}$ filter in an Amicon filter device (Merck Milipore, Massachusetts, USA) according to the manufacturer's instructions. The concentrate was aliquoted into sterile $2 \mathrm{ml}$ cryovials before freezing at $-80^{\circ} \mathrm{C}$.

\section{Virus infection experiments}

C6/36 and C6/36.wAlbB cells were seeded into 24-well plates at $2.5 \times 10^{5}$ cells per well and allowed to attach for $24 \mathrm{~h}$ at $28{ }^{\circ} \mathrm{C}$. Infection with each virus strain was performed in triplicate wells, at multiplicities of infection (MOI) of 0.1, 1 or 10 in FBS-free RPMI-1640 medium (Sigma-Aldrich, Castle Hill, Australia). The virus was allowed to adsorb for $2 \mathrm{~h}$ before the inoculum was removed, the monolayers were washed twice with sterile PBS and then incubated at $28{ }^{\circ} \mathrm{C}$ in fresh maintenance media [RPMI-1640 containing 25 mM HEPES (SigmaAldrich) supplemented with 2\% FBS (Gibco) and 1\% Glutamax (Sigma-Aldrich)]. Supernatants were harvested from three independent replicate wells every $24 \mathrm{~h}$ for 8 days from cultures infected with flaviviruses. Because alphaviruses replicate much faster than flaviviruses, supernatants for these viruses were sampled every $8 \mathrm{~h}$ up to $48 \mathrm{~h}$ post-infection $(8,16,24,32,40$ and $48 \mathrm{~h})$, then every $24 \mathrm{~h}$ until day $6(72,96,120$ and $144 \mathrm{~h})$ and finally at day $8(192 \mathrm{~h})$.

\section{Plaque and immunofocus assays to determine virus titres}

Infectious virus titres were determined using either plaque or immunofocus assays on Vero (African green monkey kidney) cells maintained in Dulbecco's modified Eagle's medium (DMEM) (Sigma-Aldrich) containing 5\% $\mathrm{v} / \mathrm{v}$ foetal bovine serum (FBS, Gibco) and 1\% L-glutamine (Invitrogen, Carlsbad, USA) at $37{ }^{\circ} \mathrm{C}$ in an atmosphere of $5 \% \mathrm{v} / \mathrm{v} \mathrm{CO}_{2} /$ air. Cells were seeded in 24-well plates at $2.0 \times 10^{5}$ cells per well and incubated overnight at $37{ }^{\circ} \mathrm{C}$. Confluent monolayers were infected with $200 \mu \mathrm{l}$ of serial ten-fold dilutions of virus for $2 \mathrm{~h}$ at $37^{\circ} \mathrm{C}$, with gentle rocking every $15 \mathrm{~min}$. A $1 \mathrm{ml}$ overlay $(1: 1 \mathrm{v} / \mathrm{v})$ consisting of $8 \% \mathrm{w} / \mathrm{v}$ carboxy-methyl cellulose (CMC, Sigma-Aldrich) and Medium 199 (Sigma-Aldrich) was added to each well and plates incubated at $37{ }^{\circ} \mathrm{C}$ in an atmosphere of $5 \% \mathrm{v} / \mathrm{v} \mathrm{CO}_{2} /$ air. After the desired length of incubation (i.e. 2 days for SINV, 3 days for RRV and BFV, 4 days for KUNV and ZIKV KU365780, and 5 days for ZIKV MR766 and P13F/251013-18), overlay media was removed and cell monolayers were washed twice in PBS. Cells then were stained with $300 \mu \mathrm{l}$ of $0.05 \% \mathrm{w} / \mathrm{v}$ Crystal violet in $1 \% \mathrm{v} / \mathrm{v}$ formaldehyde and PBS for $1 \mathrm{~h}$, rinsed with water, dried and plaques counted.

As DENV did not produce plaques reliably with the protocol above, infectious titres were determined using immunofocus assay. Initial steps were performed as above before proceeding with the following modifications. Five days post infection, the CMC overlay was removed, and cell monolayers fixed with ice-cold (1:1 v/v) acetone-methanol (Thermo Fisher Scientific, Brisbane, Australia). Blocking was performed by the addition of $200 \mu \mathrm{l}$ of $5 \% \mathrm{w} / \mathrm{v}$ skim milk powder in PBS for $1 \mathrm{~h}$ at $37^{\circ} \mathrm{C}$. DENV-infected cells were detected using the antiFlavivirus monoclonal antibody 4G2 (TropBio, Cairns, Australia) as the primary antibody, followed by horseradish peroxidase (HRP)-conjugated goat anti-mouse IgG (Invitrogen, Carlsbad, USA) as a secondary. Infectious foci were detected using SigmaFast with DAB (SigmaAldrich), after the manufacturer's instructions. Plaque and immunofocus assays were performed in duplicate for each sample.

\section{Analyses}

Virus titres were $\log _{10}$-transformed and general linear models were used to test for statistically significant differences. The Chi-square test of association, Fisher's exact test, and a general linear model were used to 
compare the results from cell lines separately for each time point and for each MOI. Statistical analyses were performed using the IBM SPSS Statistics software (version 23.0) (SPSS Inc., Chicago, USA) and GraphPad Prism Version 7.00 (GraphPad Software, La Jolla, California USA, 2008). To enable graphing of virus titre values of 0 (no plaques), 1 was added to all values and the resulting number $\log _{10}$-transformed.

\section{Results}

Stable infection of $\mathrm{C} 6 / 36$ cells with Wolbachia strain wAlbB The presence of Wolbachia in the cytoplasm of C6/36.wAlbB cells was confirmed using FISH (Fig. 1a). The density of $w$ AlbB in the cytoplasm of infected C6/36 cells was less than $40 \%$ in early cell passages (P 1-20; data not shown), as found by other groups [49]. However, by passage 40 , the percentage of cells containing $w$ AlbB had increased from approximately $60 \%$ in passage 28 to more than $95 \%(P<0.01$ by Mann Whitney test; Fig. $1 b)$.

\section{Wolbachia strain wAlbB blocks Flavivirus replication in vitro}

All flaviviruses tested replicated to lower titres in C6/36.wAlbB cells compared to Wolbachia-free C6/36 controls, regardless of MOI. Although titres from Wolbachia-infected and control cells were similar at early time points (1-3 dpi, Fig. 2), titres of DENV produced in $\mathrm{C} 6 / 36 . w \mathrm{AlbB}$ were reduced by an average of $2-3$ logs by 8 days post-infection (dpi) (Fig. 2a-c). Titres of $\mathrm{WNV}_{\mathrm{KUN}}$ were reduced by almost 5 logs, particularly at later time points during infection (6-8 dpi) (Fig. $2 \mathrm{~d}-\mathrm{f})$, although virus remained detectable until the end of the experiment. Only with ZIKV did we observe a complete cessation in replication due to $w$ AlbB presence (Fig. 3). Replication of ZIKV African strain MR766 was reduced to a point where no infectious virus particles could be detected by plaque assay, except for $1 \mathrm{dpi}$ post-infection and at the high MOI of 10 (Fig. $3 \mathrm{a}-\mathrm{c}$ ). Titres of Brazilian strain ZIKV-KU365780 were reduced by at least $6 \operatorname{logs}$ at $8 \mathrm{dpi}$ across all MOI (Fig. 3d-f). For the French Polynesian strain $\mathrm{H} / \mathrm{PF} / 2013$, initial replication in C6/36.wAlbB cells resulted in virus titres comparable to titres from control $\mathrm{C} 6 / 36$ cells, but titres became undetectable at 3 dpi (Fig. 3g-i). For both Brazilian and French Polynesian ZIKV strains, we observed that the higher the MOI the longer it took before infectious virus disappeared from $\mathrm{C} 6 / 36 . w A l b B$ cells.

\section{Wolbachia strain wAlbB blocks Alphavirus replication in vitro}

The replication of the three alphaviruses tested was reduced in C6/36.wAlbB cells compared to controls, across all MOI (Fig. 4). The magnitude of
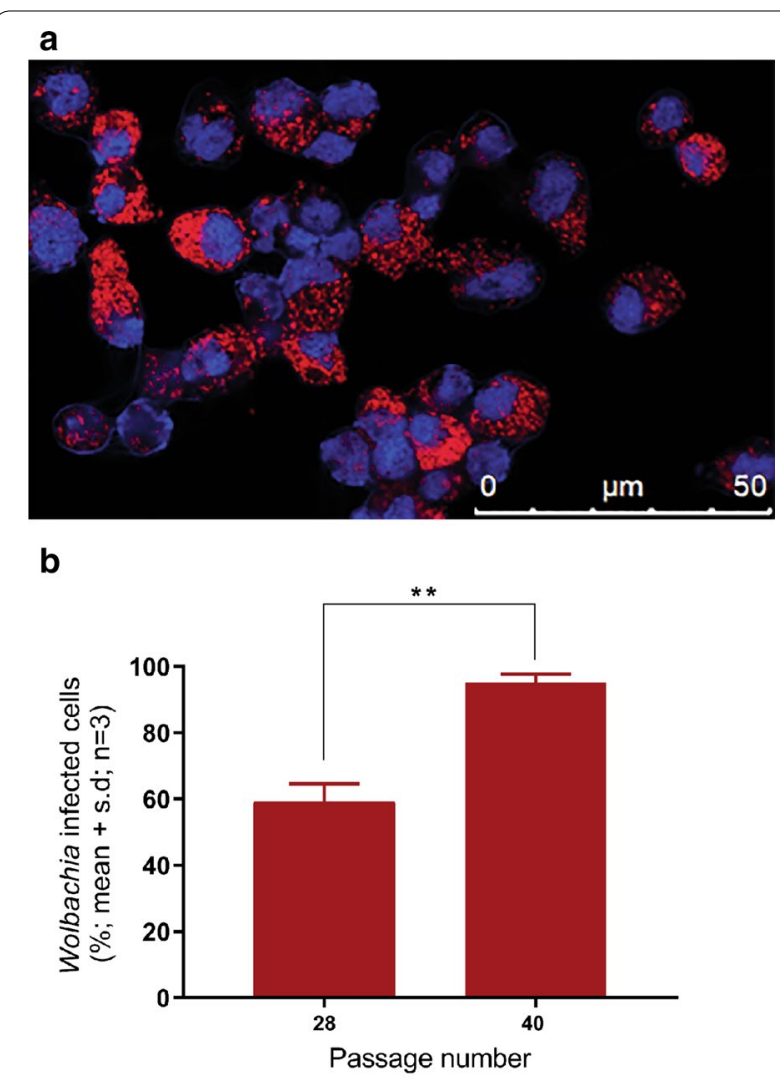

Fig. 1 Detection of Wolbachia wAlbB by Fluorescent in situ hybridization of C6/36.wAlbB cells. a Carbocyanine5-labelled oligonucleotide probe corresponding to nucleotide sequences in Wolbachia 165 rRNA within the cytoplasm of the host cell (red). Cell nuclei stain blue with DAPI. b Proportion of cells containing Wolbachia wAlbB detectable by FISH between passages 28 and 40 . Images were taken at a magnification of 100x. Error bars represent the standard deviation of the mean of three independent cell culture samples. Statistical significance was calculated by Mann Whitney test $(P<0.05$, denoted by **)

Wolbachia-mediated blocking of BFV (Fig. 4a-c) and SINV (Fig. 4d-f) replication increased with time. For $\mathrm{BFV}$, this ranged from a reduction of $1-2 \operatorname{logs}$ at $8-24$ $\mathrm{h}$ post-infection (hpi) to more than $4 \operatorname{logs}$ at $72-144 \mathrm{hpi}$ in wAlbB-infected cells versus controls. BFV and SINV could be detected in culture supernatants for longer postinfection at high MOI rather than low MOI, although all viruses had disappeared from supernatants of $w$ AlbBinfected cells by 144 hours into the experiment. At the MOI of 0.1, SINV could not be detected at $96 \mathrm{hpi}$; however, at the MOI of 10 , replication was detected for a further 48 hours. RRV was largely undetectable at MOI of 0.1 and 1 (Fig. $4 \mathrm{~g}-\mathrm{i}$ ), except for $8 \mathrm{hpi}$ at MOI 1. However, at MOI of 10, infectious virus was detected until $32 \mathrm{hpi}$ and thereafter only re-appeared at $72 \mathrm{hpi}$ (Fig. 4i). There 

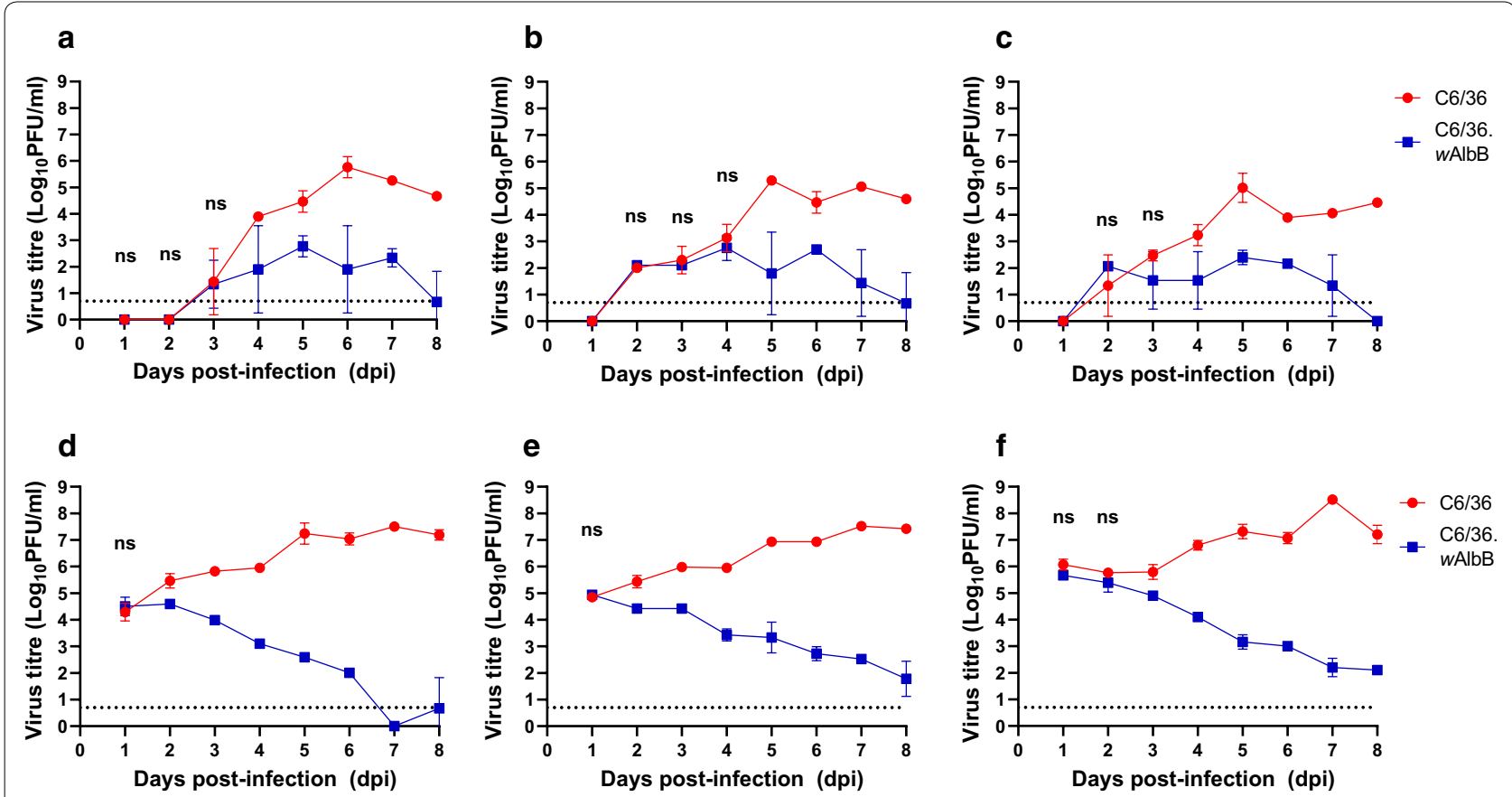

Fig. 2 Kinetics of virus production following infection of C6/36 and C6/36-WAlbB cells with DENV 2 strain ET300 and WNV $V_{\text {KUN }}$ at MOI of 0.1 (a, d), 1 $(\mathbf{b}, \mathbf{c})$ and 10 (c, f). Means and standard deviations (error bars) for each time point are shown ( $n=3$ wells per time point). Abbreviations: PFU, plaque forming unit; ns, virus yields that are not significantly different $(P>0.05)$ between cell lines. Limit of detection for the plaque assay is shown as a dotted line

were no significant differences (general linear model $F_{(1,}$ $\left.{ }_{6)}=2.33, P=0.18\right)$ in the extent of Wolbachia-mediated blocking between flaviviruses and alphaviruses.

\section{Discussion}

A large body of evidence has now accumulated documenting the ability of transinfected Wolbachia to block virus replication [50-52]. Although most reports have concerned the field-released $w$ Mel strain, the ability of $w$ AlbB to block virus replication is being increasingly explored. Our results show that yields of infectious virus from a range of flaviviruses were consistently reduced in wAlbB-infected C6/36 cells versus Wolbachia-free cells. Our data are consistent with previous reports of the ability of $w$ AlbB to block ZIKV in other cell lines [53], although we observed much stronger blocking in the $C 6 / 36$ system compared to this earlier report. It is also consistent with previous reports of DENV [40] and $\mathrm{WNV}_{\mathrm{KUN}}$ [54] blocking in mosquitoes. Our data, using the C6/36 cell line background, confirm that the RNAi response is not an absolute requirement for Wolbachia-mediated blocking [55] since these cells are defective in this pathway [56]. Despite the reduction in virus replication observed due to Wolbachia, infectious DENV and $\mathrm{WNV}_{\mathrm{KUN}}$ were produced and remained detectable in most treatments until the end of the experiment. By contrast, ZIKV levels rapidly fell below levels of detection for most MOI treatments and virus strains. The results suggest the blocking effect of $w$ AlbB may be stronger for ZIKV than DENV, similar to observations from Ae. aegypti mosquitoes [40].

Significant blocking in $w$ AlbB-infected cells was also observed for RRV, BFV and SINV compared to uninfected cells. This is similar to other studies utilizing alphaviruses, such as Semliki Forest virus [57]. In contrast to DENV and $\mathrm{WNV}_{\mathrm{KUN}}$, infectious yields of alphaviruses in $w$ AlbB-infected cells fell to undetectable levels much earlier in the experiment compared to control cells. The speed at which alphavirus stopped being produced in Wolbachia-infected cells was a function of inoculum size, with high MOI treatments producing detectable virus for much longer than low MOIs. For both BFV and SINV, we observed $\mathrm{a} \sim 24 \mathrm{~h}$ delay in the time taken for the MOI 10 infection to become undetectable in comparison to the MOI 1 infection. This delay due to higher initial inoculum was also observed with ZIKV, particularly the Asian genotype strains. Interestingly, the same pattern was not observed for DENV or $\mathrm{WNV}_{\mathrm{KUN}}$. These data suggest that, for some viruses, the block hypothesized to occur early in infection, possibly at the virus translation stage [57-59], may be delayed if the initial virus population is large. A possible explanation is that a large starting population size allows the virus to partially overcome the initial challenge imposed by Wolbachia in 

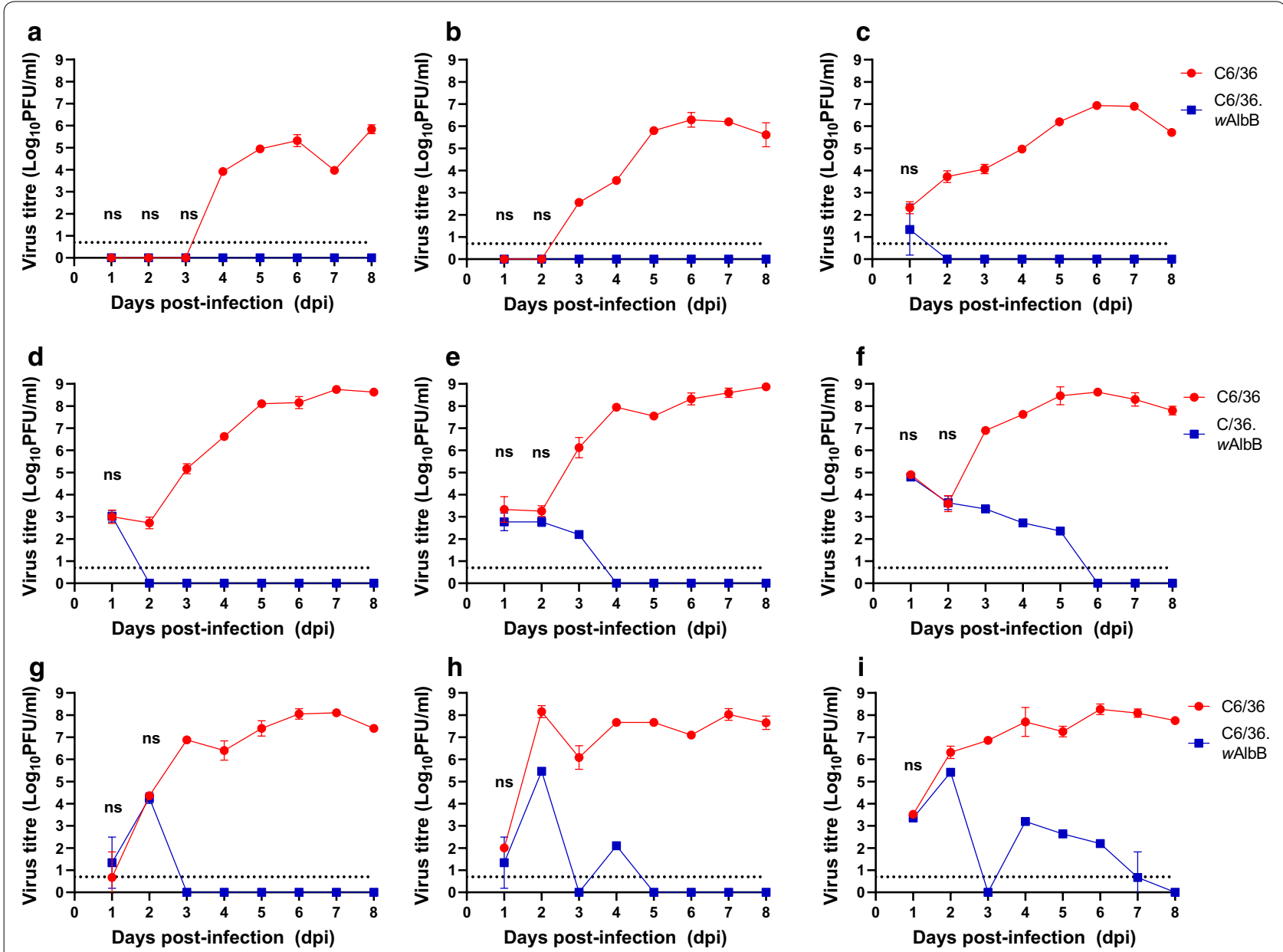

Fig. 3 Kinetics of virus production following infection of C6/36 and C6/36.wAlbB cells with three strains of ZIKV at MOI of 0.1, 1 and 10 (left to right). African strain MR766 (a-c), Brazilian strain KU365780 (d-f), and French Polynesian strain H/PF/2013 (g-i). Means and standard deviations (error bars) for each time-point are shown ( $n=3$ wells per time-point). Abbreviations: PFU, plaque forming unit; ns, virus yields that are not significantly different $(P>0.05)$ between cell lines. Limit of detection for the plaque assay is shown as a dotted line

these cells. However, subsequent cycles of infection may be hampered by low numbers of progeny viruses and the ability of Wolbachia to reduce the infectivity of these progeny $[58,60]$, ultimately causing extinction of the virus.

Our data show that differences in the ability of $w$ AlbB to block viruses is related to individual virus species and strains rather than broader taxonomic groupings such as genera or families. For example, among the alphaviruses, RRV production was undetectable for most time points while BFV production was reduced at later time points (72-96 hpi). Within the flaviviruses, a similar pattern was observed for ZIKV, whereby the prototype strain MR766 was undetectable at most time points but Asian genotype strains persisted much longer, and, in some cases, infectious virus briefly rebounded from almost zero levels. These brief rebounds were also observed for the three alphaviruses, as well as $\mathrm{WNV}_{\mathrm{KUN}}$, and were not always a function of high initial MOI. Subtle replication differences among virus species and strains [61] may result in varying abilities of arboviruses to persist and, potentially evade the blocking effect of Wolbachia.

\section{Conclusions}

Our results have implications for using $w$ AlbB to control arboviruses. As wMelPop appears unable to become established in wild mosquito populations [26] and $w$ Mel may not survive at high temperatures in the field [62], alternative strains of Wolbachia need to be considered for biocontrol. Invasion of $w \mathrm{AlbB}$-infected Ae. aegypti has been achieved for a small area in Malaysia [52] and has been associated with a reduction in the incidence of dengue in an endemic area [43]. Our study adds to the growing body of evidence that $w$ AlbB is able to inhibit a wide range of mosquito-borne viruses and supports the case for a broader virus surveillance 

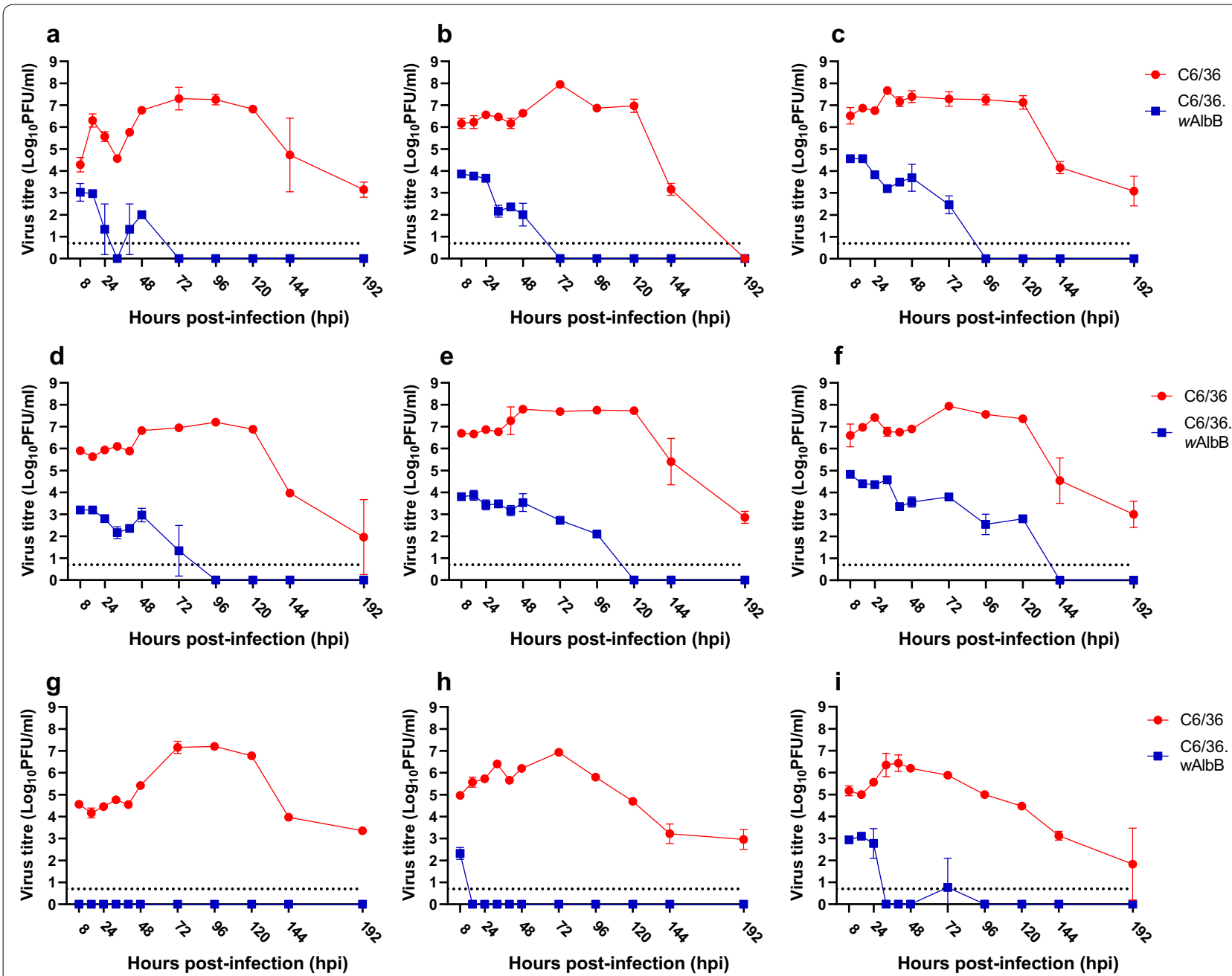

Fig. 4 Kinetics of virus production following infection of C6/36 and C6/36.wAlbB cells with the alphaviruses BFV (a-c), SINV (d-fi) and RRV (g-i) in $\mathrm{C} 6 / 36$ at $\mathrm{MOl}$ of $0.1,1$ and 10. Means and standard deviations (error bars) for each time-point are shown ( $n=3$ wells per time-point). Abbreviations: PFU, plaque forming unit. Limit of detection for the plaque assay is shown as a dotted line

programmes in areas where the strain is being evaluated to determine whether it has an impact on diseases other than dengue.

\section{Abbreviations}

BFV: Barmah Forest virus; CHIKV: chikungunya virus; CMC: carboxymethylcellulose; DENV: dengue virus; DTT: dithiothreitol; FBS: fetal bovine serum; FISH: fluorescent in situ hybridization; MOI: multiplicity of infection; PBS: phosphate-buffered saline; PFA: paraformaldehyde; RRV: Ross River virus; SINV: Sindbis virus; WNV $_{\text {KUN: }}$ : West Nile virus (Kunjin strain); ZIKV: Zika virus.

\section{Acknowledgements}

We thank Professor Jason Rasgon (Pennsylvania State University) for the gift of the wAlbB-infected Aa23 cell line, Mrs Debbie Phillips (Queensland University of Technology) for technical assistance and Dr Louise Marquart and Mr Lachlan Webb (QIMR Berghofer) for their help with statistical analysis. We thank Professor Paul Young (The University of Queensland) for the DENV ET300 strain, and Drs Van-Mai Cao-Lormeau (Institute Louis Malarde), Julian Druce (Victorian Infectious Diseases Reference Laboratory) and Dr Pedro
Vasconcelos for Zika virus strains. We would also like to acknowledge the lan Potter Foundation (Australia) for an equipment grant enabling the purchase of a fluorescent microscope at QUT.

\section{Authors' contributions}

OE performed experiments, analyzed data and wrote the first draft of the manuscript. JGA contributed materials. All authors contributed to conceptualizing the project, and writing and editing the manuscript. All authors read and approved the final manuscript.

\section{Funding}

The study was funded by a National Health and Medical Research Council grant to FDF (APP1020817) and internal Queensland University of Technology (QUT) and Institute for Health and Biomedical Innovation (IHBI) grants. OE was funded by the government of Nigeria through the TeTFund Scholarship and a QUT part-scholarship.

\section{Availability of data and materials}

All data is presented within the paper and materials are available upon reasonable request. 
Ethics approval and consent to participate

Not applicable.

\section{Consent for publication}

Not applicable.

\section{Competing interests}

The authors declare that they have no competing interests.

\section{Author details}

1 School of Biomedical Sciences and Institute of Health and Biomedical Innovation, Queensland University of Technology, Herston, QLD 4006, Australia. ${ }^{2}$ Department of Microbiology, Chukwuemeka Odumegwu Ojukwu University, Uli, Nigeria. ${ }^{3}$ Mosquito Control Laboratory, Queensland Institute of Medical Research Berghofer, Herston, QLD 4006, Australia.

Received: 17 October 2019 Accepted: 3 February 2020 Published online: 10 February 2020

\section{References}

1. Guzman MG, Halstead SB, Artsob H, Buchy P, Farrar J, Gubler DJ, et al. Dengue: a continuing global threat. Nat Rev Microbiol. 2010;8(Suppl. 12):S7-16.

2. Bhatt $S$, Gething PW, Brady OJ, Messina JP, Farlow AW, Moyes $C L$, et al. The global distribution and burden of dengue. Nature. 2013;496:504-7.

3. Mlakar J, Korva M, Tul N, Popovic M, Poljsak-Prijatelj M, Mraz J, et al. Zika virus associated with microcephaly. N Engl J Med. 2016;374:951-8.

4. Brasil P, Pereira JP Jr, Moreira ME, Ribeiro Nogueira RM, Damasceno L, Wakimoto $\mathrm{M}$, et al. Zika virus infection in pregnant women in Rio de Janeiro. N Engl J Med. 2016;375:2321-34.

5. Hubalek Z. European experience with the West Nile virus ecology and epidemiology: could it be relevant for the New World? Viral Immunol. 2000:13:415-26.

6. Marfin AA, Gubler DJ. West Nile encephalitis: an emerging disease in the United States. Clin Infect Dis. 2001;33:1713-9.

7. Russell RC. Vectors vs. humans in Australia-who is on top down under? An update on vector-borne disease and research on vectors in Australia. J Vector Ecol. 1998;23:1-46.

8. Tesh RB. Arthritides caused by mosquito-borne viruses. Annu Rev Med. 1982;33:31-40.

9. Aaskov JG, Mataika JU, Lawrence GW, Rabukawaqa V, Tucker MM, Miles JA, Dalglish DA. An epidemic of Ross River virus infection in Fiji, 1979. Am J Trop Med Hyg. 1981;30:1053-9.

10. Dunstan RA, Seed CR, Keller AJ. Emerging viral threats to the Australian blood supply. Aust N Z J Public Health. 2008;32:354-60.

11. Kurkela S, Rätti O, Huhtamo E, Uzcátegui NY, Nuorti JP, Laakkonen J, et al. Sindbis virus infection in resident birds, migratory birds, and humans, Finland. Emerg Infect Dis. 2008;14:41-7.

12. Iturbe-Ormaetxe I, Walker T, O'Neill SL. Wolbachia and the biological control of mosquito-borne disease. EMBO Rep. 2011;12:508-18.

13. Werren JH. Biology of Wolbachia. Annu Rev Entomol. 1997:42:587-609.

14. Werren JH, Baldo L, Clark ME. Wolbachia: master manipulators of invertebrate biology. Nat Rev Microbiol. 2008;6:741-51.

15. Zug R, Hammerstein P. Still a host of hosts for Wolbachia: analysis of recent data suggests that $40 \%$ of terrestrial arthropod species are infected. PLOS ONE. 2012;7:e38544.

16. de Oliveira CD, Goncalves DS, Baton LA, Shimabukuro PH, Carvalho FD, Moreira LA. Broader prevalence of Wolbachia in insects including potential human disease vectors. Bull Entomol Res. 2015;105:305-15.

17. Moreira LA, Iturbe-Ormaetxe I, Jeffery JA, Lu G, Pyke AT, Hedges LM, et al. A Wolbachia symbiont in Aedes aegypti limits infection with dengue, chikungunya, and plasmodium. Cell. 2009;139:1268-78.

18. Walker T, Johnson PH, Moreira LA, Iturbe-Ormaetxe I, Frentiu FD, McMeniman CJ, et al. The wMel Wolbachia strain blocks dengue and invades caged Aedes aegypti populations. Nature. 2011;476:450-3.

19. Hussain M, Lu G, Torres S, Edmonds JH, Kay BH, Khromykh AA, Asgari S. Effect of Wolbachia on replication of west nile virus in a mosquito cell line and adult mosquitoes. J Virol. 2013:87:851-8.
20. Bian G, Xu Y, Lu P, Xie Y, Xi Z. The endosymbiotic bacterium Wolbachia induces resistance to dengue virus in Aedes aegypti. PLoS Pathog. 2010;6:e1000833.

21. Mousson L, Zouache K, Arias-Goeta C, Raquin V, Mavingui P, Failloux AB. The native Wolbachia symbionts limit transmission of dengue virus in Aedes albopictus. PLoS Negl Trop Dis. 2012;6:e1989.

22. Frentiu FD, Zakir T, Walker T, Popovici J, Pyke AT, van den Hurk A, et al. Limited dengue virus replication in field-collected Aedes aegypti mosquitoes infected with Wolbachia. PLoS Negl Trop Dis. 2014:8:e2688.

23. Hoffmann AA, Montgomery BL, Popovici J, Iturbe-Ormaetxe I, Johnson $\mathrm{PH}$, Muzzi F, et al. Successful establishment of Wolbachia in Aedes populations to suppress dengue transmission. Nature. 2011;476:454-7.

24. O'Neill SL, Ryan PA, Turley AP, Wilson G, Retzki K, Iturbe-Ormaetxe I, et al. Scaled deployment of Wolbachia to protect the community from dengue and other Aedes transmitted arboviruses. Gates Open Res. 2018;2:36.

25. Ferguson NM, Kien DT, Clapham H, Aguas R, Trung VT, Chau TN, et al. Modeling the impact on virus transmission of Wolbachia-mediated blocking of dengue virus infection of Aedes aegypti. Sci Transl Med. 2015;7:279ra237.

26. Nguyen TH, Nguyen HL, Nguyen TY, Vu SN, Tran ND, Le TN. Field evaluation of the establishment potential of WMelPop Wolbachia in Australia and Vietnam for dengue control. Parasites Vectors. 2015;8:563.

27. McMeniman CJ, Lane RV, Cass BN, Fong AW, Sidhu M, Wang YF, O’ Neill SL. Stable introduction of a life-shortening Wolbachia infection into the mosquito Aedes aegypti. Science. 2009;323:141-4.

28. van den Hurk AF, Hall-Mendelin S, Pyke AT, Frentiu FD, McElroy K, Day $A$, et al. Impact of Wolbachia on infection with chikungunya and yellow fever viruses in the mosquito vector Aedes aegypti. PLoS Negl Trop Dis. 2012;6:e1892.

29. MCMeniman CJ, O'Neill SL. A virulent Wolbachia infection decreases the viability of the dengue vector Aedes aegypti during periods of embryonic quiescence. PLoS Negl Trop Dis. 2010;4:e748.

30. Yeap HL, Mee P, Walker T, Weeks AR, O'Neill SL, Johnson P, et al. Dynamics of the "popcorn" Wolbachia infection in outbred Aedes aegypti informs prospects for mosquito vector control. Genetics. 2011;187:583-95.

31. Ross PA, Endersby NM, Hoffmann AA. Costs of three Wolbachia infections on the survival of Aedes aegypti larvae under starvation conditions. PLoS Negl Trop Dis. 2016;10:e0004320.

32. Ye YH, Carrasco AM, Frentiu FD, Chenoweth SF, Beebe NW, van den Hurk $\mathrm{AF}$, et al. Wolbachia reduces the transmission potential of dengueinfected Aedes aegypti. PLoS Negl Trop Dis. 2015;9:e0003894.

33. Dutra HL, Rocha MN, Dias FB, Mansur SB, Caragata EP, Moreira LA. Wolbachia blocks currently circulating Zika virus isolates in Brazilian Aedes aegypti mosquitoes. Cell Host Microbe. 2016;19:771-4.

34. Aliota MT, Peinado SA, Velez ID, Osorio JE. The wMel strain of Wolbachia reduces transmission of Zika virus by Aedes aegypti. Sci Rep. 2016;6:28792.

35. Aliota MT, Walker EC, Uribe Yepes A, Velez ID, Christensen BM, Osorio JE. The wMel strain of Wolbachia reduces transmission of chikungunya virus in Aedes aegypti. PLoS Negl Trop Dis. 2016;10:e0004677.

36. Hoffmann AA, Iturbe-Ormaetxe I, Callahan AG, Phillips BL, Billington K, Axford JK, et al. Stability of the wMel Wolbachia infection following invasion into Aedes aegypti populations. PLoS Negl Trop Dis. 2014;8:e3115.

37. Ulrich JN, Beier JC, Devine GJ, Hugo LE. Heat sensitivity of wMel Wolbachia during Aedes aegypti development. PLoS Negl Trop Dis. 2016;10:e0004873.

38. Ross PA, Wiwatanaratanabutr I, Axford JK, White VL, Endersby-Harshman NM, Hoffmann AA. Wolbachia infections in Aedes aegypti differ markedly in their response to cyclical heat stress. PLoS Pathog. 2017;13:e1006006.

39. Ross PA, Ritchie SA, Axford JK, Hoffmann AA. Loss of cytoplasmic incompatibility in Wolbachia-infected Aedes aegypti under field conditions. PLoS Negl Trop Dis. 2019;13:e0007357.

40. Ant TH, Herd CS, Geoghegan V, Hoffmann AA, Sinkins SP. The Wolbachia strain wAu provides highly efficient virus transmission blocking in Aedes aegypti. PLoS Pathog. 2018;14:e1006815.

41. Xi Z, Khoo CC, Dobson SL. Wolbachia establishment and invasion in an Aedes aegypti laboratory population. Science. 2005:310:326-8.

42. Ritchie SA, van den Hurk AF, Smout MJ, Staunton KM, Hoffmann AA. Mission Accomplished? We need a guide to the 'post release' world of Wolbachia for Aedes-borne disease control. Trends Parasitol. 2018;34:217-26.

43. Nazni WA, Hoffmann AA, Noor Afizah A, Cheong YL, Mancini MV, Golding N, et al. Establishment of Wolbachia strain WAlbB in 
Malaysian populations of Aedes aegypti for dengue control. Curr Biol. 2019;29:4241-8.

44. Igarashi A. Isolation of a Singh's Aedes albopictus cell clone sensitive to dengue and chikungunya viruses. J Gen Virol. 1978;40:531-44.

45. O'Neill SL, Pettigrew MM, Sinkins SP, Braig HR, Andreadis TG, Tesh RB. In vitro cultivation of Wolbachia pipientis in an Aedes albopictus cell line. Insect Mol Biol. 1997;6:33-9.

46. Frentiu FD, Robinson J, Young PR, McGraw EA, O’Neill SL. Wolbachiamediated resistance to dengue virus infection and death at the cellular level. PLoS ONE. 2010;5:e13398.

47. Dobson SL, Marsland EJ, Veneti Z, Bourtzis K, O'Neill SL. Characterization of Wolbachia host cell range via the in vitro establishment of infections. Appl Environ Microbiol. 2002;68:656-60.

48. Xi Z, Dean JL, Khoo C, Dobson SL. Generation of a novel Wolbachia infection in Aedes albopictus (Asian tiger mosquito) via embryonic microinjection. Insect Biochem Mol Biol. 2005;35:903-10.

49. Raquin V, Valiente Moro C, Saucereau Y, Tran FH, Potier P, Mavingui P. Native Wolbachia from Aedes albopictus blocks chikungunya virus infection in cellulo. PLoS ONE. 2015;10:e0125066.

50. Caragata EP, Dutra HL, Moreira LA. Exploiting intimate relationships: controlling mosquito-transmitted disease with Wolbachia. Trends Parasitol. 2016;32:207-18.

51. Lindsey ARI, Bhattacharya T, Newton ILG, Hardy RW. Conflict in the intracellular lives of endosymbionts and viruses: a mechanistic look at Wolbachia-mediated pathogen-blocking. Viruses. 2018;10:141.

52. Ross PA, Turelli M, Hoffmann AA. Evolutionary ecology of Wolbachia releases for disease control. Annu Rev Genet. 2019;53:93-116.

53. Schultz MJ, Isern S, Michael SF, Corley RB, Connor JH, Frydman HM. Variable inhibition of Zika virus replication by different Wolbachia strains in mosquito cell cultures. J Virol. 2017;91:e00339-17.

54. Joubert DA, Walker T, Carrington LB, De Bruyne JT, Kien DH, Hoang Nle T, et al. Establishment of a Wolbachia superinfection in Aedes aegypti mosquitoes as a potential approach for future resistance management. PLoS Pathog. 2016;12:e1005434.
55. Terradas G, McGraw EA. Wolbachia-mediated virus blocking in the mosquito vector Aedes aegypti. Curr Opin Insect Sci. 2017;22:37-44.

56. Brackney DE, Scott JC, Sagawa F, Woodward JE, Miller NA, Schilkey FD, et al. C6/36 Aedes albopictus cells have a dysfunctional antiviral RNA interference response. PLoS Negl Trop Dis. 2010;4:e856.

57. Rainey SM, Martinez J, McFarlane M, Juneja P, Sarkies P, Lulla A, et al. Wolbachia blocks viral genome replication early in infection without a transcriptional response by the endosymbiont or host small RNA pathways. PLoS Pathog. 2016;12:e1005536.

58. Bhattacharya T, Newton ILG, Hardy RW. Wolbachia elevates host methyltransferase expression to block an RNA virus early during infection. PLoS Pathog. 2017;13:e1006427.

59. Schultz MJ, Tan AL, Gray CN, Isern S, Michael SF, Frydman HM, Connor JH. Wolbachia wStri blocks Zika virus growth at two independent stages of viral replication. MBio. 2018;9:e00738-18.

60. Koh C, Audsley MD, Di Giallonardo F, Kerton EJ, Young PR, Holmes EC, McGraw EA. Sustained Wolbachia-mediated blocking of dengue virus isolates following serial passage in Aedes aegypti cell culture. Virus Evol. 2019;5:vez012.

61. Willard KA, Demakovsky L, Tesla B, Goodfellow FT, Stice SL, Murdock CC, Brindley MA. Zika virus exhibits lineage-specific phenotypes in cell culture, in Aedes aegypti mosquitoes, and in an embryo model. Viruses. 2017;9:383.

62. Ross PA, Hoffmann AA. Continued susceptibility of the wMel Wolbachia infection in Aedes aegypti to heat stress following field deployment and selection. Insects. 2018;9:78.

\section{Publisher's Note}

Springer Nature remains neutral with regard to jurisdictional claims in published maps and institutional affiliations.
Ready to submit your research? Choose BMC and benefit from:

- fast, convenient online submission

- thorough peer review by experienced researchers in your field

- rapid publication on acceptance

- support for research data, including large and complex data types

- gold Open Access which fosters wider collaboration and increased citations

- maximum visibility for your research: over $100 \mathrm{M}$ website views per year

At BMC, research is always in progress.

Learn more biomedcentral.com/submissions 